\section{International collaboration to protect health workers from infectious diseases in Ecuador}

\author{
Marie-Claude Lavoie, ${ }^{1}$ \\ Annalee Yassi, ${ }^{2}$ Elizabeth Bryce, ${ }^{2,3}$ \\ Ronaldo Fujii, ${ }^{2}$ Milton Logronio, ${ }^{4}$ \\ Maritza Tennassee, ${ }^{1}$ and the \\ Healthy Hospital Project Team
}

Suggested citation: Lavoie MC, Yassi A, Bryce E, Fujii R, Logronio $M$, Tennassee $M$, et al. International collaboration to protect health workers from infectious diseases in Ecuador. Rev Panam Salud Publica. 2010;27(5):396-402.

\section{SYNOPSIS}

The Healthy Hospital Project, an international collaboration, aimed to strengthen Ecuador's capacity to promote healthier and safer hospitals by reducing occupational transmission of infectious diseases. Team members conducted a needs assessment to identify workplace hazards and health risks in three hospitals. A survey of health care workers' knowledge and practices of occupational health $(\mathrm{OH})$ and infection control (IC) revealed positive practices such as a medical waste disposal program and widespread dissemination of health information. Challenges identified included a high frequency of recapping needles and limited resources for workers to apply consistent IC measures. The survey revealed underreporting of needlestick injuries and limited $\mathrm{OH}$ and safety (OHS) training. Therefore, project collaborators organized a training workshop for health care workers that aimed to overcome the identified obstacles by integrating interdisciplinary local, national, and international stakeholders to build capacity and institutionalize work-related infection prevention and control measures. The knowledge transferred and experience gained led to useful hospital-based projects and serves as a basis for implementation of other OHS projects nationwide. International interdisciplinary, interinstitutional collaboration in OHS and IC can build capacity to address OHS concerns in health care.

Key words: infection control; occupational health services; delivery of health care; hospitals; Ecuador.
Transmission of hospital-acquired infections is a global public health concern that affects the delivery of health care services (1). The World Health Organization (WHO) estimates that at any given time more than 1.4 million people worldwide have infections they acquired in hospitals (1). Health care workers are at risk of exposure to a multitude of infectious diseases, including, but not limited to, tuberculosis (TB), influenza, human immunodeficiency virus (HIV), and hepatitis B. In some countries, hospital employees are three times more likely than the general population to contract TB (2). Overall, airborne infections pose a significant hazard to health care workers $(2,3)$, especially in low- and middle-income countries (4). A similar risk is present for occupational transmission of bloodborne pathogens (5). The prevalence of hepatitis B among health care workers is estimated to be up to fivefold higher than that in the general population in some areas (6). Most exposures among health care workers are caused by percutaneous injuries from sharp objects, such as needles, contaminated with blood or body fluids (5). A staggering $90 \%$ of bloodborne infections occur in low-income countries, highlighting the vulnerability of front-line health care workers in these geographic areas $(2,5)$. Health care workers are often not aware of possible risks because they lack training in occupational health and infection control; alternatively, they may have the knowledge but do not have access to the necessary equipment to protect themselves (7). The implementation of environmental and administrative infection and occupational controls, as well as health care workers' practices, are important in reducing nosocomial infections as well as in ensuring that health care workers can perform their work safely (2).

\section{HEALTHY HOSPITAL PROJECT}

The Healthy Hospital Project-an international collaboration between the Pan American Health Organization (PAHO), Health Canada, the Ecuadorian Ministry of Public Health, the University of British Columbia (UBC), and Vancouver Coastal Health Authority-aims to strengthen Ecuador's capacity to promote healthier and safer hospitals by reducing occupational

\footnotetext{
1 Pan American Health Organization, Washington, D.C., United States. Send correspondence to: Marie-Claude Lavoie, Area of Sustainable Development and Environmental Health, Pan American Health Organization, 525 23rd Street, N.W., Washington, D.C. 20037, United States; e-mail: lavoiema@paho.org

2 University of British Columbia, Vancouver, British Columbia, Canada.

3 Vancouver Coastal Health, Vancouver, British Columbia, Canada.

4 Ministry of Public Health, Quito, Ecuador.
} 
transmission of infectious diseases. The objectives of this initiative were to:

- Strengthen or establish occupational health and safety committees in the selected hospitals;

- Assess occupational hazards present in the hospitals, focusing primarily on biological hazards;

- Build human capacity for preventing, controlling, and eliminating occupational risks; and

- Foster international collaboration for promoting and protecting the health of health care workers.

The Healthy Hospital Project fits under the framework of the PAHO Regional Plan on Workers' Health (8) and the PAHO Regional Goals for Human Resources for Health (9). This project also aligns with the WHO Global Plan of Action on Workers' Health (10), which urges member countries to implement occupational health and safety policies and programs in this health care sector.

\section{Project phases}

The project was conducted in three facilities in Ecuador over a period of one year in 2007-2008. The Healthy Hospital Project included three major sequential phases: (1) identifying workplace hazards, (2) training in occupational health and infection control, and (3) implementing hospital-based projects.

Phase 1: Identifying workplace hazards (May-October 2007). During the first stage, the project's collaborators aimed to produce a baseline assessment on current environmental and occupational risks as well as on the best practices present in the selected hospitals.

Team members were selected from the international, national, and local project's partners according to their areas of expertise in occupational health, infection control, clinical care, management, health policy, and health promotion. The Ministry of Public Health from Ecuador selected national and local health professionals to dedicate their time and expertise to this project. The interdisciplinary team conducted a baseline assessment in 13 medical units from three public Ecuadorian hospitals. In consultation with hospital employees, the team prioritized the hospital units according to the facility's areas of concerns and the level of risk of exposure to infectious diseases among health care workers. Two hospitals were located in Quito and one was a remote hospital in the Amazon region. The Ecuadorian Ministry of Public Heath selected the two hospitals in Quito on the basis of volume of patients and need for resources. The hospital in the Amazon was selected because it was the reference hospital for that region.

In order to systematically identify occupational and environmental hazards, team members adopted a previously developed occupational health and infection control audit tool and adapted it for this setting, translated it into Spanish, and ensured that the terms used were familiar to local professionals. The audit tool used previously in Canada (11) and South Africa (12) includes a list of occupational hazards, including physical, chemical, biological, ergonomic, safety, and psychological hazards. Under each hazard classification, the evaluator completed the workplace assessment by indicating whether the environment and practices were satisfactory, required correction but were not an immediate hazard, or required immediate correction. For example, under the biological hazard section, if the evaluator observed that there was no sharps disposal at point of use, the person would indicate that immediate correction was needed, as this setting increased the risk of needle-stick injuries among health care workers. (The audit tool developed will soon be available for downloading to use as a paper product and as a web-based surveillance tool, with instructions in its use, accessible under a Creative Commons License held by PAHO and UBC.)

With the result of the needs assessment, team members identified strengths and challenges at each health care facility. For example, best practices observed included a well-established medical waste disposal program that coordinated with the municipality plan, point-of-use puncture-resistant containers for the disposal of needles and sharp items, and the presence of health promotion strategies. The team also identified occupational and environmental risks in each health care facility. The workplace audits revealed that the availability and accessibility of soap and water to health care workers were quite limited as was education on hand hygiene. Another challenge identified on several occasions was the high prevalence of recapping needles before disposal. The audit also revealed opportunities for improved signage such as instructions for isolation precautions, use of personal protective equipment, and proper disposal of sharps. In addition, personal protective equipment, particularly for airborne diseases, was lacking. Also limited was spatial separation for infections spread by the droplet or airborne route.

The second instrument used was a survey administered to health care workers to obtain baseline information about their knowledge and practices related to occupational and infection control practices. The survey included questions related to the respondent's demographics, immunization coverage, exposure to body fluid and blood, and occupational health and infection control practices and knowledge. In total, the survey included 32 questions and required 10-15 minutes to complete. The questionnaire was based on a validated survey that had previously been used by the research team (13). The survey was administered to a convenience sample of 170 health care workers in the aforementioned hospitals and was facilitated by ward representatives and members of the research team. The sampling consisted of direct care and non-direct care workers from the 13 medical units who consented to complete the survey. For the purposes of the analyses, the project collaborators grouped the three hospitals, as the goal was to examine overall responses and to highlight any glaring differences by occupa- 
TABLE 1. Health care workers who responded correctly on survey questions related to knowledge on infection control and occupational health practices, by occupation, Ecuador, 2007-2008

\begin{tabular}{|c|c|c|c|c|c|c|c|c|c|c|c|c|}
\hline \multirow[b]{2}{*}{ Question } & \multicolumn{2}{|c|}{$\begin{array}{l}\text { Nurse } \\
(n=63)\end{array}$} & \multicolumn{2}{|c|}{$\begin{array}{c}\text { Physician } \\
(n=39)\end{array}$} & \multicolumn{2}{|c|}{$\begin{array}{c}\text { Allied } \\
(N=25)\end{array}$} & \multicolumn{2}{|c|}{$\begin{array}{l}\text { Administrative } \\
\quad(N=26) \\
\end{array}$} & \multicolumn{2}{|c|}{$\begin{array}{l}\text { Technical \& } \\
\text { support } \\
(n=15) \\
\end{array}$} & \multicolumn{2}{|c|}{$\begin{array}{c}\text { Total } \\
(n=168)^{\mathrm{a}}\end{array}$} \\
\hline & No. & $\%$ & No. & $\%$ & No. & $\%$ & No. & $\%$ & No. & $\%$ & No. & $\%$ \\
\hline $\begin{array}{l}\text { Drinks/food are allowed in clean storage } \\
\text { areas and in the medication room (False) } \\
\text { All needle-stick and sharp injuries must be } \\
\text { evaluated by occupational health } \\
\text { personnel responsible (True) }\end{array}$ & 59 & 93.7 & 38 & 97.4 & 21 & 84.0 & 21 & 80.8 & 14 & 93.3 & 153 & 91.1 \\
\hline $\begin{array}{l}\text { Patients with suspected tuberculosis can } \\
\text { share a room with others (False) }\end{array}$ & 49 & 77.8 & 29 & 74.4 & 19 & 76.0 & 15 & 57.7 & 14 & 93.3 & 126 & 75.0 \\
\hline $\begin{array}{l}\text { The use of gloves is recommended only } \\
\text { when the risk of blood and body fluid } \\
\text { exposure is present (False) }\end{array}$ & 39 & 61.9 & 24 & 61.5 & 16 & 64.0 & 11 & 42.3 & 10 & 66.7 & 100 & 59.5 \\
\hline $\begin{array}{l}\text { Needles should be recapped before } \\
\text { disposing (False) } \\
\text { The most effective practice to prevent } \\
\text { infections is the frequent cleaning of the } \\
\text { environment (False: washing hands is } \\
\text { the correct answer) }\end{array}$ & 34 & 54.0 & 14 & 36.0 & 9 & 36.0 & 3 & 11.5 & 3 & 20.0 & 63 & 37.5 \\
\hline
\end{tabular}

${ }^{a}$ Missing data: no designation for occupation (three cases).

tional group. The demographic profile of the participant group was generally reflective of the workforce as a whole: three-quarters $(72.8 \%)$ of the survey group were female. The survey included nurses $(36.9 \%)$, doctors $(23.1 \%)$, allied health professionals $(15.0 \%)$, administration (15.6\%), and support services (9.4\%). Most of those surveyed (70\%) had worked in the hospital for more than 6 years. Workers 40 to 49 years old $(39.0 \%)$ were the largest age cohort, followed by the 30 - to 39 -year-old group $(27.0 \%)$ and workers 50 years or older $(23.9 \%)$. Overall, $29 \%$ of those surveyed were unionized workers.

The goal of the survey was entirely descriptive, with no intent to compare across facilities. However, the project collaborators noted that there were no significant differences between hospitals with regard to knowledge about injuries from needle sticks and sharps or about recapping needles. Across all occupational groups, fewer than $25 \%$ of respondents had received an occupational health and safety orientation upon hiring. The overall training in occupational health and safety was relatively short, with $35.9 \%$ of respondents receiving one hour or less of total training. The largest proportion of workers receiving more than one hour of training across the three facilities was for waste disposal $(48.2 \%)$, infection control $(47.9 \%)$, hand hygiene $(45.8 \%)$, personal protective equipment $(36.1 \%)$, needle-stick injuries $(33.7 \%)$, isolation procedures $(24.2 \%)$, patient lifting procedures $(12.0 \%)$, and violence prevention (5.4\%). As shown in Table 1, workers' were very knowledgeable about procedures banning food and drinks in clean storage areas and treatment rooms $(91.1 \%)$ and the need to follow up on needle-stick injuries (87.5\%). Physicians were significantly less knowledgeable than nurses with respect to knowledge about recapping needles (36\% compared with $54 \%$ ), with administrative staff scoring particularly poorly $(11.5 \%)$ as expected, since they do not generally handle sharps. Among respondents, $43 \%$ reported having had an occupational exposure to blood and bodily fluids in the previous two years; however, only $26 \%$ of the exposed workers reported their exposure. The highest compliance rates were for "washing hands between care of patients" $(77.4 \%)$ and "getting help lifting" (59.0\%). The lowest compliance rates were for "procedures with HIV and hepatitis B patients" $(11.2 \%)$ and "eye protection compliance" (15.7\%). The overall self-rated knowledge level was generally low for all questions. The highest self-reported response with a "very good" confidence level was in the use of sterile gloves (59.5\%) and use of a surgical gown or apron $(54.1 \%)$.

Phase 2: Training in occupational health and infection control (October 2007). Team members prepared the training content based on the findings of the occupational health and infection control audit tool and the surveys completed during the initial process of the project. The objectives of the workshop were to:

- Increase awareness of the occupational and infection control hazards present in the health care sector, focusing on biological hazards;

- Strengthen occupational health and safety committees;

- Increase knowledge of international guidelines related to occupational health and safety for health care workers;

- Enable health professionals to share knowledge, expand understanding, and enhance occupational health services for health care workers; and

- Foster international, intersectoral, and interinstitutional collaboration of occupational health in the health care sector.

Participants $(n=29)$ were from various sectors and professions. Representatives from the Ministry of Pub- 
TABLE 2. Survey of knowledge change among health and safety personnel after training in occupational health and infection control $(n=19)$, Ecuador, 2007-2008

\begin{tabular}{|c|c|c|c|c|c|}
\hline Subject & $\begin{array}{c}\text { Score } \\
\text { pretraining, \% }\end{array}$ & $\mathrm{SD}^{\mathrm{a}}$ & $\begin{array}{c}\text { Score } \\
\text { posttraining, \% }\end{array}$ & SD & $P$ value \\
\hline Prevention of needle-stick injuries & 26.3 & \pm 45.2 & 73.7 & \pm 45.2 & $<0.001$ \\
\hline Importance of frequent hand washing & 21.1 & \pm 41.9 & 47.4 & \pm 51.3 & 0.056 \\
\hline Appropriate use of gloves & 63.2 & \pm 49.6 & 57.9 & \pm 50.7 & 0.331 \\
\hline General principle of tuberculosis isolation & 73.7 & \pm 45.2 & 68.4 & \pm 47.8 & 0.716 \\
\hline Reporting work-related injury & 94.7 & \pm 22.9 & 94.7 & \pm 22.9 & $\ldots{ }^{b}$ \\
\hline \multicolumn{6}{|l|}{ Ban on storage or consumption of food where } \\
\hline potentially infectious materials are present & 94.7 & \pm 22.9 & 100 & \pm 0 & 0.331 \\
\hline Total test score & 53.38 & \pm 15.68 & 63.16 & \pm 12.88 & 0.008 \\
\hline
\end{tabular}

a $\mathrm{SD}=$ standard deviation.

$\mathrm{b} \ldots=$ no difference observed.

lic Health, unions, occupational health and safety committee members, front-line health care workers, support personnel (such as janitorial staff), and hospital managers from the three selected hospitals were present. The format of the workshop included presentations, problem-solving exercises, small group discussions, group presentations by participants, and occupational hazard map exercises. Group activities were organized to promote international collaboration as well as interinstitutional and intrainstitutional collaboration and exchange of occupational health and infection control practices. The international collaboration was fostered by a multilateral exchange of information and resources among participants. For example, during the workshop, some presenters shared information about local practices, while others made presentations on international surveillance systems and guidelines. Throughout the activities of the workshop, participants were encouraged to apply the occupational hierarchy principles: optimally, occupational hazards are controlled directly at the source, then between the source and the workers (along the path), and then directly by the workers (e.g., personal protective equipment and training). The presentations included an introduction to occupational health and infection control, safe needle technology, solutions for underresourced and remote health care services, and risk management, among other subjects. The exercises included creating risk maps, utilizing each of the three hospitals' floor plans. The risks were identified, discussed, and categorized by a group of representatives affiliated with each hospital. Priorities for the risk maps were determined and three hospital-based projects were created to focus on each hospital's major concern, considering impact and feasibility. The educational materials provided to participants included a combination of local, national, and international resources. For example, the checklists in PAHO's manual Workers' Health and Safety in the Health Sector (14) were used to assist in strengthening the health and safety committee, as they contain information on assessing workplace hazards. The toolkit Protecting Healthcare Workers: Preventing Needlestick Injuries developed by $\mathrm{WHO} / \mathrm{PAHO}$ in collaboration with the United States National Institute for Occupational Safety and Health was also used to provide informa- tion on the occupational risks associated with needlestick injuries and preventive measures. To support participants in implementing infection control practices at the local level, Clean Care Is Safer Care (1) resources, such as posters and pamphlets, were also provided for dissemination in local health care facilities.

To gain insight into the efficacy of the training, the project team designed a pre- and postevaluation instrument that gathered information on the participants' demographics, self-perception of knowledge and practices, and general evaluation of practices and knowledge. The self-perception section was designed to capture the extent of confidence with respect to knowledge, whereas the general evaluation section was designed to capture the level of knowledge per se, as the two constructs are both considered important determinants of practice.

From our total attendance of 29 individuals, 19 individuals were able to complete the questionnaires at the beginning and end of the event. The other 10 participants either arrived late or left early and were therefore not eligible. Because of small numbers, the research team made only three findings, but they were important. First, overall knowledge did improve from the preworkshop to the postworkshop, as shown in Table 2. Also observed was a significant change in knowledge about proper procedures with regard to recapping needles. Needle recapping is known to be the most frequent cause of needle-stick injuries among health care workers. Thus, this finding highlights an important achievement of the workshop. It was noteworthy that knowledge of the importance of hand washing increased from a low around $21 \%$ to about $47 \%$. Despite repeatedly stressing the importance of hand washing as the most important measure to prevent transmission of infectious diseases, there was no significant improvement in response to this question and fewer than half the participants answered it correctly. This particular finding highlighted not only the need to increase awareness of the importance of hand washing across all hospitals studied but also the need to make hand hygiene accessible in order to improve compliance. After the workshop, $93 \%$ of participants were confident in their ability to organize an occupational health and safety workshop in their workplace. 
The workshop concluded with an action-oriented exercise in which participants were encouraged to develop a plan of action for their health care facility to improve the health and safety of health care workers as well as control and reduce the spread of infectious diseases. Participants used the risk map prepared during the workshop to identify areas of priorities and to plan future actions. For example, participants from one facility decided to conduct a hospital-wide educational campaign to inform health care workers about their occupational exposure in order to promote awareness of the risk of exposure to biological hazards for health care workers and their preventive measures. Participants were encouraged to link with their occupational health and safety committee and other strategic partners to plan and conduct their microprojects.

Phase 3: Implementation of hospital-based projects (October 2007 to January 2008). The health and safety committee in each health care facility, with the support of the Ministry of Public Health, was responsible for delivering training sessions in the facility after the train-the-trainer workshop. More than 350 health care workers attended the hospital-based training seminars that ensued. The Ministry of Health in collaboration with the local institution provided training and information to the staff related to occupational health and infection control. For each facility, the type and duration of training varied as each institution customized activities according to its priorities. All three hospitals had an awareness campaign on preventing needlestick injuries and on the importance of hand washing, promoting a culture of safety throughout the hospital by engaging all health care personnel. As part of this activity, in one hospital, the occupational health and safety committees met with hospital managers to advocate for consistent availability of soap, water, and towels. These efforts led to improved procurement and distribution of soap to ensure its consistent availability. Overall, it also led to increased resources for occupational health and infection control. Additionally, the Ministry of Public Health and PAHOEcuador, jointly with the Occupational Safety and Health Committee and the Nosocomial Committee members at the hospitals, organized and delivered a workshop focusing on preventing needle-stick injury and on basic measures to control and prevent infections. In addition, the Ministry of Public Health continued to provide leadership in this area and developed and disseminated national resources on policies and programs for hospitals on occupational health and safety.

\section{Summary points}

There is widespread agreement that limited resources, knowledge, and training pose barriers to optimizing occupational health and safety in hospitals (13, 15-17). As the environmental workplace audits conducted in this study revealed, health care workers often do not have regular access to essential resources and equipment, such as soap and personal protective gear. One of the most basic, yet critical, measures to prevent and reduce transmission of infectious diseases is proper hand washing (18). The committee informed hospital managers about the occupational risks as well as the benefits of investing in preventive measures, noting that preventing infectious disease reduces morbidity and mortality in health care workers, decreases absenteeism (19), and reduces workers' compensation costs (20). The committee also highlighted the fact that infection control serves to protect the health of patients, other health care workers, and the general public (21).

The findings also indicated common misconceptions about work practices. For example, many health care workers believed that needles needed to be recapped. This gap of information poses health threats to health care workers, as recapping is a main cause of needle-stick injuries and consequently increased risk of contracting blood-borne diseases (22). This finding highlighted the need for preventive messages to be communicated regularly to staff. Because the workforce of a hospital changes as new health care workers and medical and allied health professionals and students join, continuous occupational health and safety education is needed to ensure workers can protect themselves effectively (23).

Another misconception that emerged during the project was associated with the causes of work-related injuries and illnesses (24), as workers are often thought to bear sole responsibility for their health and safety at work $(25,26)$. Stigmatizing workers who sustain injuries or exposures is known to limit their ability to access occupational health services. Working conditions (long hours, physical exertion, overtime, and overload) (27), organizational and institutional structure (13), and exposure to uncontrolled occupational hazards are beyond the control of workers yet affect their health and the delivery of health care services to patients. According to study results, although most workers stated that they knew how to report injuries, fewer than a quarter of them actually reported their needle-stick injuries. Health care workers need to be informed about their occupational risks, be knowledgeable about preventive measures, and have access to occupational health services.

It is increasingly well documented that decisions about policies in this area of infectious disease transmission, and the content of specific training programs, are best developed in a collaborative manner (28). Communication about safety within health care organizations concerning employees, and especially between occupational health and infection control personnel, is important in creating safe workplaces (29). Coordinating occupational health services with other departments that support the infection control objectives can promote improved surveillance for infection in health care workers as well as assist with investigating exposure and implementing preventive measures (30). With regard to ownership of the Healthy 
Hospitals Project at the local level, the Ministry of Public Health played an important role in reinforcing and training each occupational health and safety committee in the selected hospitals through ongoing support.

\section{LIMITATIONS}

While the Healthy Hospital Project focused primarily on preventing and controlling biological risks, there is a need to expand and broaden this initiative to address other occupational hazards and promote safe and healthy work environments in a comprehensive context. From a methodologic point of view, it is important to note that, because of funding constraints, the project needed to be planned, delivered, and evaluated in less than a one-year period and with a very small budget. Thus, the data collected were for descriptive purposes alone. The methodologic challenges in data collection across all three phases (phase 1, convenience sampling obtained by different means across hospitals and departments; phase 2, very small number completing pre- and postworkshop surveys; phase 3, same as for phase 1) led to the team deciding to scrap all statistical analyses. In the future, appropriately designed complex public health intervention trial methodology (31), possibly using cluster-randomized trial methodology and conducted in partnership with trained researchers from local universities, should be considered as a strategy to pursue rigorous evaluation of such projects and each of their components and to assess their impact in the medium and long term.

\section{CONCLUSION}

The project accomplished all its stated goals: it strengthened occupational health and safety committees in the selected hospitals; it assessed occupational hazards present in the hospitals, focusing on biological hazards; it built human capacity for preventing, controlling, and eliminating occupational risks; and it fostered international collaboration for promoting and protecting the health of health care workers. As such, the Healthy Hospitals Project serves as a model for occupational health and safety capacity building in health care settings. Results of the audit and the health care workers' survey revealed that limited resources, knowledge, and training pose barriers to optimizing occupational health and safety in hospitals. By integrating interdisciplinary, interagency, local, national, and international stakeholders, the project built the capacity and institutionalization of occupational hazard prevention measures. The Ministry of Public Health played an important role in reinforcing and training each occupational health and safety committee in the selected hospitals through leadership and ongoing support. The transfer of the Healthy Hospitals Project to the local level is an important component for the sustainability of the project, which has been incorporated as part of the Ministry of Public Health's regular programming. The Healthy Hospitals Project high- lighted the need to educate and increase awareness among health care workers and hospital managers of occupational risks present in hospital settings, develop a culture of prevention, and address misconceptions about the causes of work-related injuries and illnesses. PAHO is now expanding the Healthy Hospital Project to other countries in the region. Finally, while implementation of Healthy Hospital Projects need not wait for further study, appropriately designed intervention studies and implementation research would be very useful in informing decision makers how best to implement the various phases and optimize the effectiveness of the various project components.

\section{SINOPSIS}

\section{Colaboración internacional para proteger al personal sanitario de las enfermedades infecciosas en Ecuador}

El objetivo del Proyecto Hospitales Saludables, resultado de una colaboración internacional, fue fortalecer la capacidad del Ecuador de promover hospitales más saludables y seguros al reducirse la transmisión ocupacional de las enfermedades infecciosas. Los miembros del equipo realizaron una evaluación en tres hospitales para detectar los peligros y los riesgos para la salud en el lugar de trabajo. Tras llevar a cabo una encuesta de conocimientos y prácticas de los trabajadores sanitarios en lo que se refiere a salud ocupacional $y$ control de infecciones, se encontraron aspectos positivos, como un programa de eliminación de desechos médicos y la difusión generalizada de información sanitaria. En cuanto a los retos, se detectó una alta frecuencia de volver a colocar el protector de la punta de la aguja antes de desecharla y recursos limitados para que los trabajadores puedan aplicar uniformemente medidas de control de infecciones. En esa misma encuesta se reveló que se notificaba una cantidad menor de la real de pinchazos en los dedos y una capacitación limitada en salud y seguridad ocupacionales. Por consiguiente, como parte del proyecto y con miras a superar los obstáculos señalados, se organizó un taller de capacitación para los trabajadores sanitarios en el cual participaron los interesados directos locales, nacionales e internacionales en diferentes disciplinas, a efectos de desarrollar capacidades $e$ institucionalizar medidas de control y prevención de infecciones relacionadas con el trabajo. Los conocimientos transferidos y la experiencia adquirida dieron lugar a proyectos útiles basados en hospitales y sirven de base para ejecutar otros proyectos de salud y seguridad ocupacionales en todo el país. La colaboración interdisciplinaria e interinstitucional a nivel internacional en salud y seguridad ocupacionales y control de infecciones tiene el potencial de desarrollar capacidades para atender estos problemas en las actividades de atención de la salud.

Palabras clave: control de infecciones; servicios de salud del trabajador; prestación de atención de salud; hospitales; Ecuador. 


\section{REFERENCES}

1. Pittet D, Allegranzi B, Storr J, Donaldson L. "Clean Care Is Safer Care": the Global Patient Safety Challenge 2005-2006. Int J Infect Dis. 2006;10(6):419-24. Available from: http://www.who.int/patient safety/events/05/global_challenge/en/ index.html. Accessed 25 January 2010.

2. Menzies D, Joshi R, Pai M. Risk of tuberculosis infection and disease associated with work in health care settings. Int J Tuberc Lung Dis. 2007;11(6): 593-605.

3. Aziz AM. Tuberculosis and the implications for healthcare workers in hospitals. Br J Nurs. 2008;17(7):442-7.

4. Fica CA, Cifuentes DM, Ajenjo HM, Jemenao PM, Zambrano OA, Febre VN, et al. Tuberculosis en el personal de salud. Rev Chilena Infectol. 2008;25(4): 243-55.

5. Pruss-Ustun A, Rapiti E, Hutin Y. Sharps injuries: global burden of disease from sharps injuries to health-care workers. WHO Environmental Burden of Disease Series No. 3. Geneva: WHO; 2003.

6. Ciorlia LA, Zanetta DM. Hepatitis B in healthcare workers: prevalence, vaccination and relation to occupational factors. Braz J Infect Dis. 2005;9(5):384-9.

7. Mulanovich GS, Lescano AG, Gonzaga VE, Blazes DL. Occupational health in the developing world: a role for the medical research community? J Occup Environ Med. 2007;49(11):1184-8.

8. Pan American Health Organization. Regional plan on workers' health for the Americas. Washington, DC: PAHO; 2001. Available from: http://www. paho.org/English/GOV/CSP/csp2710-e.pdf. Accessed 7 October 2009.

9. Pan American Health Organization. Regional goals for human resources for health 2007-2015. Washington, DC: PAHO; 2007. Available from: http:// www.who.int/occupational_health / regions/en/oehamregplan.pdf. Accessed 7 October 2009.

10. World Health Organisation. Workers' health: global plan of action. Washington, DC: WHO; 2007. Available from: http://www.who.int/gb/ebwha/pdf files/WHA60/A60_R26-en.pdf. Accessed 7 October 2009.

11. Bryce E, Scharf S, Walker M, Walsh A. The infection control audit: the standardized audit as a tool for change. Am J Infect Control. 2007;35(4):271-83.
12. Yassi A, Nophale L, Dybka L, Bryce E, Kruger W, Spiegal J. Building capacity to secure healthier and safer working conditions for healthcare workers: a South African-Canadian collaboration. Int J Occup Environ Health. 2009;15(4): 360-70.

13. Yassi A, Lockhart K, Copes R, Kerr M, Corbiere M, Bryce E. Determinants of healthcare workers' compliance with infection control procedures in healthcare. Healthc Q. 2007;10(1)44-52.

14. Pan American Health Organization/ World Health Organization. Worker's health and safety in the health sector: a manual for managers and administrators. Washington, DC: $\mathrm{PAHO} / \mathrm{WHO}$; 2005. Available from: http://www.bvsde. ops-oms.org/ssmanual/interface.htm. Accessed 7 October 2009

15. Yassi A, Hancock T. Patient safetyworker safety: building a culture of safety to improve healthcare worker and patient well-being. Healthc Q. 2005;8:32-8.

16. Yassi A, Ostry AS, Hatter B, De Boer HM. Joint health and safety committee education and the value of bipartite cooperation in the healthcare sector in British Columbia, Canada. Int J Occup Environ Health. 2005;11(3):305-12.

17. Yassi A. Health promotion in the workplace-the merging of the paradigms. Methods Inf Med. 2005;44(2):278-84

18. Rosenthal V, Guzman S, Safdar N. Reduction in nosocomial infection with improved hand hygiene in intensive care units of a tertiary care hospital in Argentina. Am J Infect Control. 2005; 33(7):392-7.

19. Wilde JA, McMillan JA, Serwint J, Butta J, O'Riordan MA, Steinhoff MC. Effectiveness of influenza vaccine in health care professionals: a randomized trial. JAMA. 1999;281(10):908-13.

20. Yassi A, Pawson D, Leary T, Sikorski J, Parent D, Gilbert M, et al. Trends in workplace injuries, illness, and policies in healthcare across Canada: workers' compensation patterns and policy changes in healthcare organizations. Report for Health Canada. Ottawa, Ontario: Health Canada; 2004.

21. Lundstrom T, Pugliese G, Bartely J, Cox J, Guither C. Organizational and environmental factors that affect worker health and safety and patient outcomes. Am J Infect Control. 2002;30(2):93-106.
22. World Health Organization. Aidememoire for a strategy to protect health workers from infection with bloodborne viruses. Geneva: WHO; 2003.

23. Yassi A, Bryce E, Moore D, Janssen R, Copes R, Bartlett K, et al. Protecting the faces of health care workers: knowledge gaps and research priorities for effective protection against occupationallyacquired respiratory infectious diseases. Vancouver: Occupational Health and Safety Agency of British Columbia; 2004.

24. Kline TJ, Willness C, Ghali WA. Determinants of adverse events in hospitalsthe potential role of patient safety culture. J Healthc Qual. 2008;30(1):11-7.

25. Halbesleben JR, Wakefield BJ, Wakefield DS, Cooper LB. Nurse burnout and patient safety outcomes: nurse safety perception versus reporting behavior. West J Nurs Res. 2008;30(5):560-77.

26. Bognar A, Barach P, Johnson JK, Duncan RC, Birnbach D, Woods D, et al. Errors and the burden of errors: attitudes, perceptions, and the culture of safety in pediatric cardiac surgical teams. Ann Thorac Surg. 2008;85(4):1374-81.

27. Shirom A, Nirel N, Vinokur AD. Overload, autonomy, and burnout as predictors of physicians' quality of care. J Occup Health Psychol. 2006;11(4):328-42.

28. Baka A, Fusco F, Puro V, Vetter N, Skinhoj P, Ott K, et al. A curriculum for training healthcare workers in the management of highly infectious diseases. Euro Surveill. 2007;12(6):E5-6.

29. Moore D, Gamage B, Bryce E, Copes R, Yassi A. Protecting health care workers from SARS and other respiratory pathogens: organizational and individual factors that affect adherence to infection control guidelines. Am J Infect Control. 2005;33(2):88-96.

30. Sebazco S. APIC text of infection control and epidemiology. Section V, Occupational health. Washington, DC: APIC; 2005.

31. British Medical Research Council. Developing and evaluating complex interventions: new guidance. London: British Medical Research Council; 2006.

Manuscript received on 9 October 2009. Revised version accepted for publication on 29 January 2010. 